\title{
Sagittal radiographic parameters demonstrate weak correlations with pretreatment patient-reported health-related quality of life measures in symptomatic de novo degenerative lumbar scoliosis: a European multicenter analysis
}

\author{
Sayf S. A. Faraj, BSc, ${ }^{1,2}$ Marinus De Kleuver, MD, PhD, ${ }^{1}$ Alba Vila-Casademunt, MSc, ${ }^{3}$ \\ Roderick M. Holewijn, MD, ${ }^{2}$ Ibrahim Obeid, MD, ${ }^{4}$ Emre Acaroğlu, MD, ${ }^{5}$ Ahmet Alanay, MD, ${ }^{6}$ \\ Frank Kleinstück, MD, ${ }^{7}$ Francisco S. Pérez-Grueso, MD, ${ }^{8}$ and Ferran Pellisé, MD, PhD, ${ }^{3}$ \\ on behalf of the European Spine Study Group
}

'Department of Orthopedics, Radboud University Medical Center, Nijmegen, The Netherlands; '2Department of Orthopaedic Surgery, VU University Medical Center, Amsterdam, The Netherlands; '3Spine Surgery Unit, Hospital Universitari Vall d'Hebron, Barcelona, Spain; ${ }^{4}$ Spine Unit, Bordeaux University Hospital, Bordeaux, France; ${ }^{5}$ Department of Orthopedics and Traumatology, Ankara Spine Center, Ankara, Turkey; ${ }^{6}$ Department of Orthopedics and Traumatology, Acıbadem Mehmet Ali Aydınlar University, Istanbul, Turkey; ${ }^{7}$ Spine Surgery, Schultess Clinic, Zurich, Switzerland; and ${ }^{8}$ Spine Surgery Unit, Hospital Universitario La Paz, Madrid, Spain

OBJECTIVE Previous studies have demonstrated that among patients with adult spinal deformity (ASD), sagittal plane malalignment is poorly tolerated and correlates with suboptimal patient-reported health-related quality of life (HRQOL). These studies included a broad range of radiographic abnormalities and various types of ASD. However, the clinical and radiographic characteristics of de novo degenerative lumbar scoliosis (DNDLS), a subtype of ASD, may influence previously reported correlation strengths. The aim of this study was to correlate sagittal radiographic parameters with pretreatment HRQOL in patients with symptomatic DNDLS.

METHODS In this multicenter retrospective study of prospectively collected data, 74 patients with symptomatic DNDLS were enrolled based on anteroposterior and lateral 36-inch standing radiographs. Measurements included Cobb angle, coronal imbalance, pelvic incidence (PI), pelvic tilt (PT), lumbar lordosis (LL), sagittal vertical axis (SVA), thoracic kyphosis, pelvic incidence minus lumbar lordosis (PI-LL), T1-pelvic angle, and global tilt. HRQOL questionnaires included the Oswestry Disability Index (ODI), Scoliosis Research Society (SRS-22r), 36-item Short-Form Health Survey, and numeric rating scale (NRS) for back and leg pain. Correlations between radiographic parameters and HRQOL were assessed. Finally, HRQOL and increasing severity of sagittal modifiers (SVA, PI-LL, and PT) were evaluated.

RESULTS Weak correlations were found between SVA and ODI $(r=0.296, p<0.05)$ and PT with NRS back pain and the SRS pain domain $(r=-0.260, p<0.05$, and $r=0.282, p<0.05$, respectively). Other sagittal radiographic parameters did not show any significant correlation with HRQOL. No significant differences in HRQOL were found concerning the increasing severity of PT, PI-LL, and SVA.

CONCLUSIONS While DNDLS is a severe disabling condition, no noteworthy association between clinical and sagittal radiographic parameters was found through this study, demonstrating that sagittal radiographic parameters should not be considered the unique predictor of pretreatment suboptimal health status in this specific group of patients. Future studies addressing classification and treatment algorithms will have to take into account the existing subgroups of ASD. https://thejns.org/doi/abs/10.3171/2017.8.SPINE161266

KEYWORDS de novo degenerative lumbar scoliosis; sagittal radiographic parameters; health-related quality of life; adult spinal deformity

ABBREVIATIONS ASD = adult spinal deformity; BMI = body mass index; CA = Cobb angle; $\mathrm{Cl}=$ coronal imbalance; DNDLS = de novo degenerative lumbar scoliosis; $\mathrm{GT}=$ global tilt; $\mathrm{HRQOL}=$ health-related quality of life; $\mathrm{LL}=$ lumbar lordosis; $\mathrm{MCS}=$ Mental Component Summary; NRS = numeric rating scale; ODI = Oswestry Disability Index; PCS = Physical Component Summary; PI = pelvic incidence; $\mathrm{PT}=$ pelvic tilt; SF-36v2 = 36-item Short-Form Health Survey, version 2; SRS-22r = Scoliosis Research Society questionnaire, revised; SVA = sagittal vertical axis; TK = thoracic kyphosis; TPA = T1-pelvic angle.

ACCOMPANYING EDITORIAL See pp 571-572. DOI: 10.3171/2017.9.SPINE17857.

SUBMITTED November 6, 2016. ACCEPTED August 2, 2017.

INCLUDE WHEN CITING Published online March 23, 2018; DOI: 10.3171/2017.8.SPINE161266. 
$\mathrm{T}$ HE leading cause of years lived with disability in Western societies continues to be low-back pain. ${ }^{24}$ Adult spinal deformity (ASD), a condition referring to abnormal spinal curvatures among adults, constitutes one of the known causes of severe functional disability and back pain in the elderly. ${ }^{1,16}$ Subsequently, ASD significantly reduces the overall quality of life in patients with a symptomatic deformity and is one of the most frequent indications for spine surgery. ${ }^{19}$ An emphasis on healthy aging combined with rising life expectancies and recognition of the disorder will undoubtedly lead to increased surgical interventions (https://www.hcup-us.ahrq.gov/db/ nation/nis/NIS_Introduction_2014.jsp); for this reason, the matter of identifying etiology, manifestations, and treatments is becoming even more urgent.

By definition, ASD covers a broad spectrum of spine disorders that can occur during adulthood, including 1) de novo degenerative lumbar scoliosis (DNDLS), 2) an adult form of idiopathic scoliosis, and 3) fixed sagittal imbalance ${ }^{1,26}$ Depending on the type and severity of deformity, it may range from asymptomatic to severe pain and disability. Previous studies have demonstrated that among patients with ASD, sagittal plane malalignment is poorly tolerated and correlates with suboptimal health status. ${ }^{7,8,13,20}$ Since then, the focus of ASD surgery has been to address sagittal malalignment to alleviate symptoms and achieve gains in function. As a result, Schwab et al. ${ }^{21}$ developed a classification system based on the most clinically important sagittal spinopelvic modifiers (sagittal vertical axis [SVA], pelvic tilt [PT], and pelvic incidence minus lumbar lordosis [PI-LL]) associated with clinical outcome measures in ASD. This classification features strengths, including a high intrarater agreement, substantial interrater agreement, and validation in large ASD patient cohorts. ${ }^{14,23}$ However, this classification was developed based on a broad range of radiographic abnormalities and different etiologies of ASD. Recent studies have challenged this presumed impact of sagittal spinopelvic malalignment on health status and demonstrated weak correlations with health-related quality of life (HRQOL) when limiting ASD to DNDLS. 3,11

The etiology and clinical and radiographic characteristics of DNDLS are significantly different compared with other types of ASD. ${ }^{1}$ To date, insufficient evidence about the relationship between the various etiologies of ASD and HRQOL has been gathered. Based on the different subtypes of spinal deformities, etiology could be an important contributing factor to the variation found in correlation strengths between radiographic parameters and HRQOL among these subtypes. Therefore, the objective of this study is to evaluate the association between pretreatment HRQOL and sagittal radiographic parameters among a select group of patients with symptomatic DNDLS. An additional subgroup analysis was performed on patients $<70$ and $\geq 70$ years old to identify whether different age groups tolerate sagittal malalignment differently.

\section{Methods}

\section{Patient Population}

This is a multicenter retrospective study of prospective- ly collected data in patients with ASD through an IRBapproved protocol at 6 spine centers across Europe. Local research coordinators are managing data collection and data entry. A central coordinator supervises and coordinates the activities of all sites involved in the multicenter database and ensures that professional research standards are maintained throughout. Inclusion criteria are age 18 years or older, and having at least 1 of the following: 1) a spinal coronal Cobb angle (CA) $\geq 20^{\circ}$; 2) SVA $\geq 5 \mathrm{~cm} ; 3$ ) $\mathrm{PT} \geq 25^{\circ}$; or 4 ) a thoracic kyphosis (TK) $\geq 60^{\circ}$.

In this multicenter prospective database, a search was performed for patients who fit the diagnosis "DNDLS" (Fig. 1). Although discrimination between DNDLS and other forms of ASD (i.e., the adult form of idiopathic scoliosis) is not simple, ${ }^{10}$ several distinguishing characteristics of DNDLS such as age, curve location, and curve degree have been suggested. These distinguishing characteristics were implemented as inclusion criteria in the present study to acquire a specific population of patients with DNDLS.1,9 Inclusion criteria for this study were age $\geq 55$ years, a lumbar Cobb angle $10^{\circ}-55^{\circ}$, and an apex located in the lumbar region (L1-5). Symptomatic was defined as having a Scoliosis Research Society (SRS) subtotal domain score $\leq 4.0$ or Oswestry Disability Index $(\mathrm{ODI}) \geq 20$. Exclusion criteria were patients with double curves; a history of juvenile or adolescent idiopathic scoliosis; neuromuscular spinal abnormalities; metabolic spinal pathology; or previous spine surgery.

\section{Demographics and HRQOL}

Demographic data including sex, age, and body mass index (BMI) were gathered. To evaluate health status, all patients were asked to answer widely used HRQOL ques-
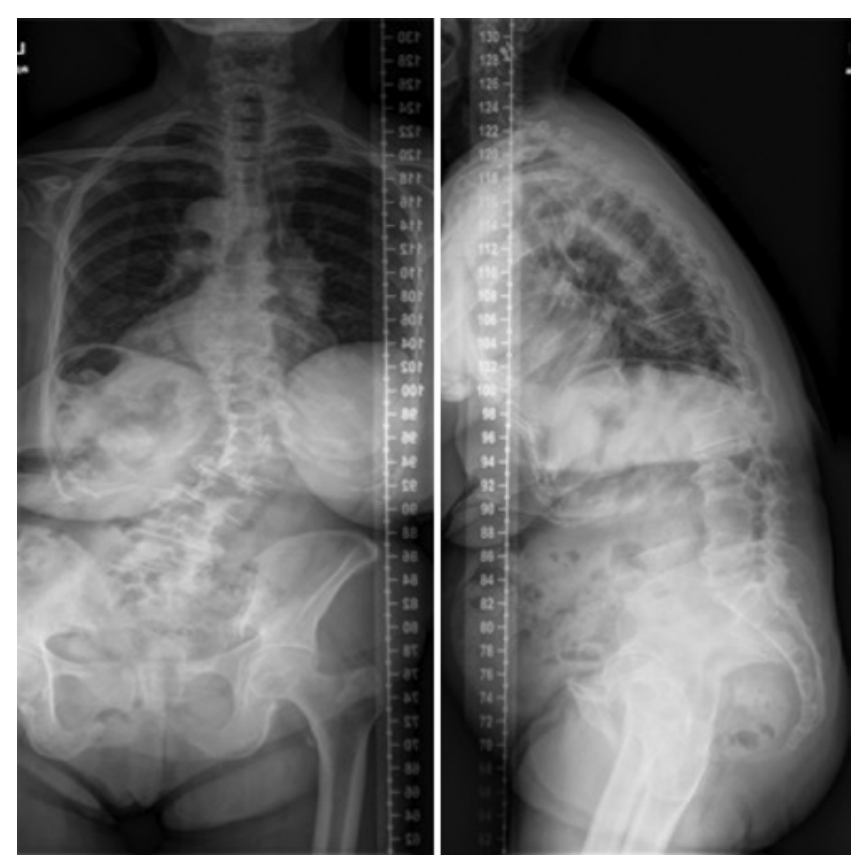

FIG. 1. Standing anteroposterior and lateral radiographs of a 73-year-old woman with symptomatic DNDLS, sagittal malalignment, and an ODI score of 62, indicating severe disability. The NRS back and leg pain scores were 10 and 7 , respectively. 
tionnaires: the ODI, SRS-22r, and 36-item Short-Form Health Survey version 2 (SF-36v2) questionnaires, and the numeric rating scale (NRS) to indicate their level of back and leg pain.

\section{Radiographic Analysis}

Each patient underwent a series of complete standing anteroposterior and lateral full-length spine radiographs. Radiographic measures were obtained using measurement software (Surgimap, Nemaris Inc.). Radiographic parameters included lumbar CA, coronal imbalance (CI; C-7 plumb line to central sacral vertical line), PI, PT, LL (L1-S1), SVA (C-7 plumb line offset from posterosuperior S-1 vertebral body corner), TK (T2-12), and PI-LL. Finally, the recently proposed T1-pelvic angle (TPA; T1 sagittal tilt + pelvic tilt) and global tilt (GT; pelvic tilt + spinal tilt angle) were measured, which both account for the compensatory pelvis mechanism observed in patients with spinal deformity and sagittal malalignment, and are least affected by the patient's position during radiographic examination. ${ }^{15,18}$ Finally, patients were classified according to the sagittal modifiers of the SRS-Schwab ASD Classification: "neutral (0)," "positive (+)," and "very positive $(++) . " 21$

\section{Statistical Analysis}

All statistical analyses were performed using SPSS statistical software (version 22, IBM Corp.). Descriptive analysis was used to calculate the demographics, HRQOL status, and radiology data. Data collection obtained in the same period was used for the analysis and tested for normal distribution (Shapiro-Wilk test). Pearson's correlation coefficient and corresponding $\mathrm{p}$ values were calculated to identify associations between pretreatment HRQOL and sagittal radiographic parameters. Level-of-associationstrengths were classified according to Evans' classification; 5 values $<0.05$ were considered statistically significant. However, we did not want the null hypothesis (i.e., that there is no association between sagittal parameters and HRQOL in patients with DNDLS) to occur because of a stringent $p$ value. Therefore, we did not correct the $\mathrm{p}$ value to adjust for multiple testing. In this way, type II error (failing to detect an effect that is present) is minimized. In addition, a 1-way ANOVA test was used to evaluate differences in HRQOL along the spinopelvic sagittal modifier grades (SVA, PI-LL, and PT). When classifying patients according to their severity of sagittal modifiers, the expected group sizes become small, which results in a larger type II error when testing. To diminish this type II error slightly, $\mathrm{p}$ values $<0.10$ were considered statistically significant instead of the usual 0.05 . Finally, patients were stratified according to age into two groups, $<70$ years (Group 1) and $\geq 70$ years (Group 2). Mean values of radiographic parameters and HRQOL were compared between age groups using a Student t-test. A p value $<0.05$ was considered statistically significant.

\section{Results}

\section{Study Population Demographics and HRQOL}

Based on the study criteria, a total of 74 patients with
DNDLS, comprising 14 men (18.9\%) and 60 women (81.1\%), were included. The mean patient age was 70 years (range 55-87 years) with a mean BMI of 25.9 (range 17.6-40.3). The mean ODI was 36.8 (range 4-70). The mean SRS subtotal was 3.0 (range 1.6-4.0). The mean SF-36v2 Mental Component Summary (MCS) and Physical Component Summary (PCS) scores were 44.4 (range 14.6-68.8) and 36.6 (range 14.6-51.6), respectively. NRS mean back and leg pain scores were 4.5 (range $0-10$ ) and 6.7 (range 0-10; Table 1).

\section{Radiographic Data}

Patients had a mean lumbar CA of $30.7^{\circ}$ (range $13.0^{\circ}-$ $51.0^{\circ}$ ), a mean CI of $18.2 \mathrm{~mm}$ (range -48.4 to $51.6 \mathrm{~mm}$ ), and a mean SVA of $47.6 \mathrm{~mm}$ (range -60.1 to $184.3 \mathrm{~mm}$ ). According to the SRS-Schwab ASD classification, the vast majority of patients with DNDLS were classified into the sagittal modifier Grades 0 or + . Table 2 presents the distribution of radiographic parameters, and Table 3 presents sagittal modifiers of the SRS-Schwab ASD classification.

\section{Correlation of Radiographic Parameters With HRQOL}

According to Evans' classification, ${ }^{5}$ PT showed a significant, but rather weak correlation with NRS back pain and the SRS pain domains $(\mathrm{r}=-0.260, \mathrm{p}<0.05$, and $\mathrm{r}$ $=0.282, \mathrm{p}<0.05$, respectively). Weak correlations were found between SVA and ODI $(r=0.296, p<0.05)$ and between coronal CA and NRS back pain $(r=0.295$, $\mathrm{p}<$ $0.05)$, SRS pain domain $(r=-0.309, p<0.05)$, SRS selfimage domain $(\mathrm{r}=-0.308, \mathrm{p}<0.05)$, and SRS subtotal $(\mathrm{r}=-0.306, \mathrm{p}<0.05)$. Of interest, GT and TPA, which both account for pelvic compensation, were not found to be associated with HRQOL (range 0.004-0.227, p > 0.05).

TABLE 1. Patient demographics and distribution of HRQOL scores at baseline

\begin{tabular}{lrrcc}
\hline Demographics & Mean & SD & Range & Coefficient of Variation* \\
\hline Age $(\mathrm{yrs})$ & 70.3 & 7.9 & $55-87$ & 0.11 \\
\hline BMI $\left(\mathrm{kg} / \mathrm{m}^{2}\right)$ & 25.9 & 4.7 & $17.6-40.3$ & 0.18 \\
\hline HRQOL & & & & \\
\hline ODI & 36.8 & 13.7 & $4-70$ & 0.37 \\
\hline SF-36v2 & & & & \\
\hline MCS & 44.8 & 14.0 & $14.6-68.8$ & 0.31 \\
\hline PCS & 36.6 & 7.4 & $14.6-51.6$ & 0.20 \\
\hline NRS & & & & \\
\hline Leg pain & 4.5 & 3.2 & $0-10$ & 0.71 \\
\hline Back pain & 6.7 & 2.2 & $0-10$ & 0.33 \\
\hline SRS-22r & & & & \\
\hline Pain & 2.8 & 0.7 & $1.0-4.2$ & 0.25 \\
\hline Mental health & 3.3 & 1.0 & $1.4-5.0$ & 0.30 \\
\hline Function & 3.2 & 0.7 & $1.5-4.2$ & 0.22 \\
\hline Self image & 2.9 & 0.7 & $1.0-4.6$ & 0.24 \\
\hline Subtotal & 3.0 & 0.6 & $1.6-4.0$ & 0.20 \\
\hline A nigher ODIand
\end{tabular}

A higher ODI and NRS score represents greater disability and greater leg or back pain, respectively.

* Coefficient of variation = standard deviation divided by the mean. 
TABLE 2. Mean radiological parameter values at baseline

\begin{tabular}{lrrcc}
\hline \multicolumn{1}{c}{ Variable } & Mean & SD & Range & $\begin{array}{c}\text { Coefficient } \\
\text { of Variation }\end{array}$ \\
\hline $\mathrm{CA}\left({ }^{\circ}\right)$ & 30.7 & 13.9 & $13.0-51.0$ & 0.45 \\
\hline $\mathrm{TPA}\left({ }^{\circ}\right)$ & 20.2 & 10.5 & $0-47.0$ & 0.52 \\
\hline $\mathrm{GT}\left({ }^{\circ}\right)$ & 27.0 & 13.3 & $1.0-60.0$ & 0.49 \\
\hline $\mathrm{SVA}(\mathrm{mm})$ & 47.6 & 47.8 & -60.1 to 184.3 & 1.00 \\
\hline $\mathrm{Cl}(\mathrm{mm})$ & 18.2 & 12.3 & -48.8 to 51.6 & 0.68 \\
\hline $\mathrm{PT}\left({ }^{\circ}\right)$ & 22.2 & 9.2 & -1.0 to 42.0 & 0.41 \\
\hline $\mathrm{PI}-\mathrm{LL}$ mismatch $\left(^{\circ}\right)$ & 11.7 & 17.2 & -30.0 to 64.0 & 1.46 \\
\hline $\mathrm{TK}\left(^{\circ}\right)$ & -39.7 & 18.6 & -78.0 to 0.0 & 0.47 \\
\hline $\mathrm{LL}\left({ }^{\circ}\right)$ & 45.1 & 17.2 & -6.0 to 80.0 & 0.38 \\
\hline $\mathrm{PI}\left({ }^{\circ}\right)$ & 56.6 & 13.0 & 28.0 to 86.0 & 0.23 \\
\hline
\end{tabular}

Further analysis did not show any significant correlations between sagittal radiographic parameters and HRQOL (Table 4).

\section{HRQOL and Sagittal Modifier Grades}

ANOVA analysis along the sagittal modifier grades of the SRS-Schwab ASD classification showed no significant worsening in HRQOL scores between "neutral (0)," "positive (+)," and "very positive (++)" grades of PT, PI-LL, and SVA malalignment ( $\mathrm{p}>0.10$; Fig. 2).

\section{Age Group Stratification}

Stratification according to age ( $<70 \mathrm{vs} \geq 70$ years) demonstrated a significant difference in TPA, GT, and SVA ( $p$ $<0.05)$. However, there were no significant differences in HRQOL scores between the two groups (Table 5).

\section{Discussion}

It is important to identify factors of suboptimal health status to optimize clinical decision-making. Previous studies, including in patients with ASD older than 18 years of age, have demonstrated that spinopelvic malalignment correlates with suboptimal patient-reported health status, and surgeons are urged to account for these parameters in the evaluation and surgical planning of ASD. In contrast, the present study found an overall weak association between several sagittal radiographic parameters and pretreatment HRQOL in patients with DNDLS (Table 4).

Statistically significant (but weak) correlations were found between SVA and ODI $(r=0.296 ; p<0.05)$ and PT with NRS back pain and the SRS pain domain ( $\mathrm{r}=$ $-0.260, p<0.05$, and $r=0.282, p<0.05$, respectively). Other sagittal radiographic parameters did not show any significant correlation with HRQOL. Furthermore, no significant differences were found in HRQOL scores among the sagittal modifier groups. The results of this study are consistent with recent studies that also limited ASD patients to DNDLS., ${ }^{3,11}$ In nonoperative- and operative-treated patients with DNDLS, Ha et al. ${ }^{11}$ demonstrated that PT and SVA were not related to higher surgical rates or disability. Although PI-LL mismatch showed statistically significant results, correlation with NRS back and leg pain
TABLE 3. SRS-Schwab ASD classification grades at baseline

\begin{tabular}{cc}
\hline SRS-Schwab Classification & No. of Patients (\%) \\
\hline PT modifier & $25(34)$ \\
\hline 0: PT $<20^{\circ}$ & $32(43)$ \\
+ : PT $20-30^{\circ}$ & $17(23)$ \\
\hline$++:$ PT $>30^{\circ}$ & \\
\hline PI-LL modifier & $28(38)$ \\
\hline $0:$ PI-LL <10 & $27(36)$ \\
\hline$+:$ PI-LL $10-20^{\circ}$ & $19(26)$ \\
\hline$++:$ PI-LL $>20^{\circ}$ & \\
\hline SVA modifier & $36(49)$ \\
\hline $0:$ SVA $<40 \mathrm{~mm}$ & $28(38)$ \\
\hline$+:$ SVA $40-95 \mathrm{~mm}$ & $10(13)$ \\
\hline$++:$ SVA $>95 \mathrm{~mm}$ &
\end{tabular}

and the ODI was also weak $(r=0.137-0.176 ; \mathrm{p}<0.05)$. Interestingly, these investigators did identify a significant difference in the ODI and NRS back and leg pain between the nonoperative and operative group, although the SVA, TPA, and PI-LL did not significantly differ between the two groups.

Similarly, Chapman et al. ${ }^{3}$ evaluated the association of sagittal spinopelvic parameters with different HRQOL questionnaires (SRS-23, ODI, and SF-12) in symptomatic DNDLS with a CA $>30^{\circ}$. Consistent with the present study's results, they found an overall very weak association between HRQOL scores and LL (range 0.02-0.19), SVA (range 0.05-0.24), PI-LL mismatch (range 0.01-0.15), and PT (range 0.17-0.11). These results strongly suggest that there are other factors contributing to suboptimal health status in this specific group of patients with ASD. Notably, they identified significant differences in ODI scores among the SVA modifier groups, suggesting that an SVA $>40 \mathrm{~mm}$ is associated with worse ODI scores. In the present study, we did not identify any significant difference when using generic (SF-36v2), disease-specific (SRS-22r and ODI), and highly specific (NRS leg and back pain) HRQOL questionnaires among the sagittal modifier groups (PT, PI-LL, and SVA). However, there was a possible trend toward worsening of ODI scores among the SVA modifier groups (Fig. 2). Recently proposed sagittal parameters GT and TPA, which are not affected by the patient's position, were also not found to be associated with health status (Table 4).

The results of the present study are not consistent with other clinical studies that demonstrated that positive sagittal malalignment has a noteworthy negative impact on health status in ASD ${ }^{7,8,13,20}$ Schwab et al. ${ }^{20}$ evaluated correlations between spinopelvic parameters and HRQOL in patients with ASD and older that 18 years of age at baseline and found a moderate significant correlation between ODI and SVA ( $\mathrm{r}=0.469, \mathrm{p}<0.05)$, PT $(\mathrm{r}=0.381, \mathrm{p}<$ $0.05)$, and PI-LL $(r=-0.450, p<0.05)$. These 3 sagittal spinopelvic parameters accounted for as much as $24 \%$ of disability and pain evaluated using the ODI (adjusted $\mathrm{r}^{2}=$ 0.24). In data obtained from the same multicentric study, Protopsaltis et al. also evaluated sagittal parameters (TPA 
TABLE 4. Pearson's correlations between radiographic parameters and HRQOL scores among 74 patients with DNDLS at baseline

\begin{tabular}{|c|c|c|c|c|c|c|c|c|c|c|}
\hline \multirow[b]{2}{*}{ Parameter } & \multirow[b]{2}{*}{ ODI } & \multicolumn{2}{|c|}{ SF-36v2 } & \multicolumn{2}{|c|}{ NRS } & \multicolumn{5}{|c|}{ SRS-22r } \\
\hline & & MCS & PCS & Back & Leg & Pain & Mental Health & Function & Self Image & Subtotal \\
\hline CA & 0.213 & -0.080 & 0.103 & 0.295 & 0.017 & -0.309 & -0.026 & -0.246 & -0.308 & -0.306 \\
\hline $\mathrm{Cl}$ & 0.057 & -0.125 & -0.170 & 0.036 & 0.060 & 0.024 & -0.101 & -0.098 & -0.165 & -0.121 \\
\hline TPA & 0.023 & 0.147 & 0.004 & -0.215 & 0.056 & 0.164 & 0.112 & -0.062 & 0.061 & 0.120 \\
\hline GT & 0.024 & 0.140 & 0.017 & -0.225 & 0.029 & 0.227 & 0.214 & -0.024 & 0.094 & 0.175 \\
\hline SVA & 0.296 & 0.022 & -0.122 & 0.010 & 0.123 & 0.070 & 0.064 & -0.181 & -0.105 & -0.050 \\
\hline PT & -0.144 & 0.185 & 0.064 & -0.260 & 0.020 & 0.282 & 0.211 & -0.020 & 0.133 & 0.222 \\
\hline PI-LL & 0.12 & 0.56 & -0.36 & -0.024 & -0.088 & 0.149 & 0.081 & -0.125 & -0.017 & 0.039 \\
\hline TK & 0.030 & 0.030 & -0.085 & -0.083 & -0.010 & -0.028 & 0.015 & -0.078 & -0.032 & -0.032 \\
\hline LL & -0.126 & -0.004 & -0.007 & 0.046 & -0.096 & -0.070 & -0.045 & 0.123 & 0.024 & -0.000 \\
\hline $\mathrm{PI}$ & 0.007 & 0.078 & -0.055 & 0.040 & -0.005 & 0.078 & 0.031 & -0.017 & -0.003 & 0.019 \\
\hline
\end{tabular}

Boldface type indicates statistical significance $(p<0.05)$.

and SVA) in patients with ASD > 18 years old and demonstrated again a moderate significant correlation with ODI (0.435 and 0.455), SF-36v2 PCS (-0.445 and -0.458), and SRS-22r (-0.358 and -0.383$).{ }^{18}$ The present study was unable to demonstrate a noteworthy correlation between TPA and SVA with ODI, SF-36v2, PCS, and SRS-22r (Table 4). In addition, PI-LL was not found to be associated with HRQOL.

We postulate that a possible explanation for this variation might be the overall indiscriminate approach toward the several types of spinal disorders of ASD, as has been argued before. ${ }^{2}$ When establishing the impact of sagittal malalignment on HRQOL in ASD, Protopsaltis et al..$^{18}$ and Schwab et al. ${ }^{20}$ included a broad range of radiographic abnormalities and etiologies of spinal disorders seen in adulthood. Similarly, their inclusion of a wide range of ages, starting from 18 years, as well as nonoperatively and operatively treated patients may account for further inconsistencies with regard to results. Based upon our results, it appears that in DNDLS disability is not specifically caused by sagittal malalignment and might most likely not be the main reason for spine surgery in this group of patients. Surgical treatment for DNDLS comprises decompression alone, limited fusion without deformity correction, or long fusion with deformity correction. In a recent study, Kleinstueck et al. ${ }^{12}$ compared the 3 aforementioned surgical procedures in DNDLS and found no differences in favorable outcomes from the patient's perspective at 2 years follow-up. Interestingly, this seems to suggest that in DNDLS, restoration of sagittal alignment might not be essential to improve outcome. Notably, the objective of this study was to evaluate the clinical impact of sagittal parameters on preoperative HRQOL in patients with DNDLS. It remains unknown whether postoperative HRQOL scores are significantly associated with sagittal parameters in this specific group of ASD patients. Takemoto et al. demonstrated that, preoperatively, the clinical impact of sagittal malalignment only accounts for a small part of ODI variance and disability in ASD. ${ }^{22}$ In contrast, they found that postoperative HRQOL was significantly associated with sagittal parameters and concluded that restoration of spinal sagittal alignment is certainly important for post- operative HRQOL in ASD. It remains unknown, however, whether postoperative HRQOL is associated with sagittal parameters in DNDLS. Future studies on the association between postoperative HRQOL and sagittal parameters in this particular subgroup of ASD are recommended.

$\mathrm{Fu}$ et al. demonstrated that radiological parameters associated with pain and disability are different for different patient age groups $(<50$ years, 50-65 years, and $>$ 65 years). ${ }^{6}$ In their multicenter prospective analysis they demonstrated that different age groups can tolerate sagittal malalignment in different ways. In elderly patients with ASD, sagittal malalignment seems to drive pain and disability, whereas the magnitude of scoliosis appears to be associated with pain and disability in relatively young patients with ASD. ${ }^{6}$ The present study found a significant difference in sagittal malalignment (TPA, GT, and SVA) between DNDLS patients $<70$ versus $\geq 70$ years old (Table 5). However, no significant difference was found in HRQOL scores. These findings appear to suggest that TPA, GT, and SVA do not drive pain and disability in elderly patients $\geq 70$ years old, in this particular subgroup of ASD. However, it is possible that elderly patients may tolerate sagittal malalignment better than relatively young patients diagnosed with DNDLS. Notably, no significant difference was found with regards to PI-LL mismatch between groups.

Adult idiopathic scoliosis features a significantly different pathophysiology and clinical characteristics in comparison with DNDLS. Adult idiopathic (nondegenerative) scoliosis is a pediatric deformity treated during adulthood ( $>18$ years of age). Over time, this pediatric curve may progress, leading to a compensatory curve, or in some instances it may be affected by secondary degeneration, causing pain and disability as patients get older. This is very different than primary mono- to multilevel disc degeneration resulting in DNDLS that typically develops after the 6th decade of life. ${ }^{1}$ In this type of ASD, the degenerative process is pivotal, primarily affecting the lumbar region. ${ }^{4,25}$ Disability and pain observed in patients with DNDLS are mainly caused by segmental instability, lateral olisthesis, rotatory slip, or degeneration of facet joints causing spinal stenosis and neurological 

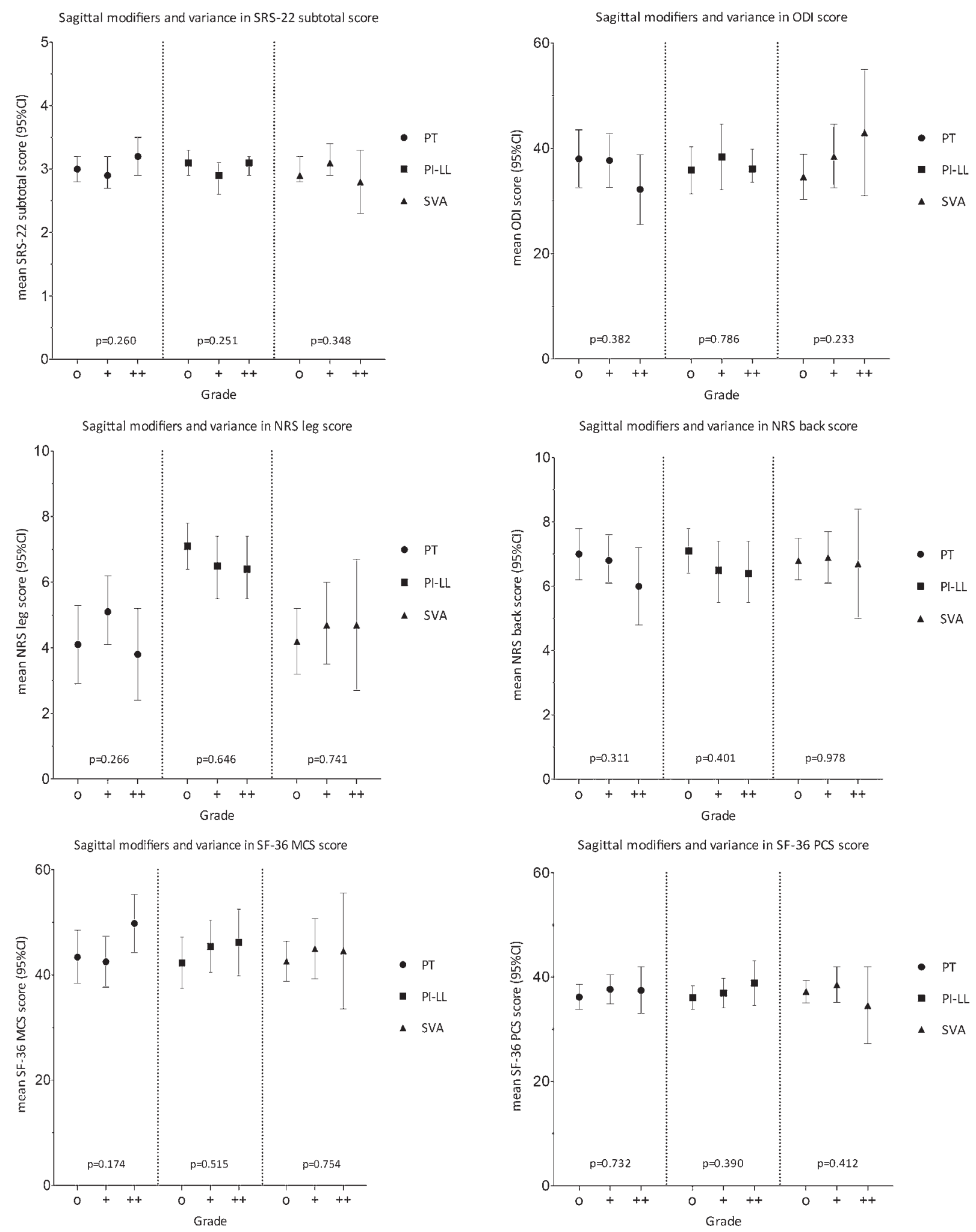

FIG. 2. HRQOL scores of SRS-Schwab ASD classification sagittal modifier grades at baseline; $p$ values reflect ANOVA in patientreported outcomes across sagittal modifier grades using a 1-way ANOVA. No significant differences were found between groups.

compression, rather than the deformity itself. ${ }^{17}$ As such, adult patients $18-55$ years old with idiopathic scoliosis are unlikely to suffer from the same distribution, localiza- tion, and intensity of degenerated areas as patients who are $\geq 55$ years old with DNDLS. Therefore, it could be that these two groups of patients should be differentiated 
TABLE 5. Age group analysis of radiographic parameters and HRQOL scores

\begin{tabular}{|c|c|c|c|}
\hline \multirow[b]{2}{*}{ Variable } & \multicolumn{2}{|c|}{ Age Group (yrs)* } & \multirow[b]{2}{*}{$\mathrm{p}$ Value } \\
\hline & $<70$ & $\geq 70$ & \\
\hline Total no. of patients & 34 & 40 & \\
\hline Age (yrs) & $63.2(4.4)$ & $76.3(4.5)$ & $<0.05$ \\
\hline $\mathrm{CA}\left({ }^{\circ}\right)$ & $29.8(9.3)$ & $31.4(9.5)$ & 0.461 \\
\hline $\mathrm{Cl}(\mathrm{mm})$ & $17.5(12.9)$ & $18.9(11.9)$ & 0.653 \\
\hline $\operatorname{TPA}\left({ }^{\circ}\right)$ & $16.1(9.6)$ & $23.9(10.0)$ & $<0.05$ \\
\hline $\mathrm{GT}\left({ }^{\circ}\right)$ & $21.3(11.7)$ & $31.8(12.9)$ & $<0.05$ \\
\hline SVA (mm) & $41.0(36.5)$ & $69.3(39.5)$ & $<0.05$ \\
\hline PT $\left({ }^{\circ}\right)$ & $20.4(7.6)$ & $23.9(10.1)$ & 0.100 \\
\hline PI-LL mismatch $\left({ }^{\circ}\right)$ & $14.5(13.1)$ & $17.5(13.2)$ & 0.328 \\
\hline $\mathrm{TK}\left({ }^{\circ}\right)$ & $39.5(18.6)$ & $39.8(18.8)$ & 0.935 \\
\hline $\operatorname{LL}\left({ }^{\circ}\right)$ & $47.2(16.9)$ & $43.6(16.7)$ & 0.360 \\
\hline $\mathrm{PI}\left({ }^{\circ}\right)$ & $55.3(13.0)$ & $57.8(13.0)$ & 0.422 \\
\hline ODI & $34.0(11.9)$ & $39.2(14.9)$ & 0.103 \\
\hline \multicolumn{4}{|l|}{ SF-36v2 } \\
\hline MCS & $44.1(13.1)$ & $45.4(14.8)$ & 0.702 \\
\hline PCS & $37.6(6.5)$ & $35.7(8.1)$ & 0.295 \\
\hline \multicolumn{4}{|l|}{ NRS } \\
\hline Back pain & $6.7(2.4)$ & $6.8(2.1)$ & 0.895 \\
\hline Leg pain & $4.5(3.5)$ & $4.5(3.0)$ & 0.974 \\
\hline \multicolumn{4}{|l|}{ SRS-22r } \\
\hline Pain & $2.8(0.7)$ & $2.7(0.8)$ & 0.814 \\
\hline Mental health & $3.3(0.8)$ & $3.3(1.1)$ & 0.961 \\
\hline Function & $3.3(0.6)$ & $3.1(0.7)$ & 0.234 \\
\hline Self image & $3.0(0.6)$ & $2.8(0.7)$ & 0.162 \\
\hline Total & $3.1(0.5)$ & $3.0(0.6)$ & 0.381 \\
\hline
\end{tabular}

Boldface type indicates statistical significance.

* Data given as mean (SD).

considering the different etiology, distribution, severity, and location of the symptomatic segments. It may be that in DNDLS an underlying diagnosis (e.g., canal stenosis) is far more important in explaining suboptimal HRQOL than spinopelvic parameters. Our results and those of others suggest that ASD is too big and heterogeneous to be considered as a single entity. ${ }^{3,11}$ Future classification and treatment algorithms will have to take into account the existing subgroups of patients included in the current large ASD diagnosis.

The results of this study should be interpreted with caution. The particular population in this study was selected based on a relatively low coronal deformity (lumbar CA $10^{\circ}-50^{\circ}$ ) and included a broad range of sagittal malalignment at baseline. Although this study focuses on a limited type of ASD with data from multiple centers, the primary limitation is the small sample size. A larger number of patients could render the trend of an association between SVA and ODI, including PT with NRS back pain and the SRS pain domain, more statistically significant. In addition, a recent study demonstrated the challenge in discriminating between DNDLS and the adult form of idiopathic scoliosis..$^{10}$ Based on inclusion criteria used in this study, the patient group studied in this paper may not be "pure" DNDLS and may have been influenced by some cases of adult forms of idiopathic scoliosis.

\section{Conclusions}

This study did not find a clinically relevant association between pretreatment sagittal radiographic parameters and HRQOL in patients with DNDLS at baseline. Weak correlations were found between sagittal parameters and HRQOL. While DNDLS is a severe disabling condition, no association between clinical and sagittal radiographic parameters was found in this study, demonstrating that sagittal radiographic parameters should not be considered the unique predictor of suboptimal health status in DNDLS. It should be noted that the present study does not provide insights into whether postoperative HRQOL is associated with sagittal parameters in this particular subgroup of ASD. Our results appear to indicate that ASD is a very heterogeneous entity and patients with DNDLS might need a different treatment strategy than adult forms of idiopathic scoliosis. Future studies addressing ASD classification and treatment algorithms will have to take into account the existing subgroups of ASD.

\section{Acknowledgments}

We thank Dr. Marianna Jonker, Department of Mathematical and Computer Science, VU University Amsterdam, for her statistical support.

\section{References}

1. Aebi M: The adult scoliosis. Eur Spine J 14:925-948, 2005

2. Angevine PD, McCormick PC: The importance of sagittal balance: how good is the evidence? J Neurosurg Spine 6:101-103, 2007

3. Chapman TM Jr, Baldus CR, Lurie JD, Glassman SD, Schwab FJ, Shaffrey CI, et al: Baseline patient-reported outcomes correlate weakly with radiographic parameters: a multicenter, prospective NIH adult symptomatic lumbar scoliosis (ASLS) study of 286 patients. Spine (Phila Pa 1976) 41:1701-1708, 2016

4. de Vries AAB, Mullender MG, Pluymakers WJ, Castelein RM, van Royen BJ: Spinal decompensation in degenerative lumbar scoliosis. Eur Spine J 19:1540-1544, 2010

5. Evans JD: Straightforward Statistics for the Behavioral Sciences. Pacific Grove, CA: Brooks/Cole Publishing, 1996

6. Fu KMG, Bess S, Shaffrey CI, Smith JS, Lafage V, Schwab F, et al: Patients with adult spinal deformity treated operatively report greater baseline pain and disability than patients treated nonoperatively; however, deformities differ between age groups. Spine (Phila Pa 1976) 39:1401-1407, 2014

7. Glassman SD, Berven S, Bridwell K, Horton W, Dimar JR: Correlation of radiographic parameters and clinical symptoms in adult scoliosis. Spine (Phila Pa 1976) 30:682-688, 2005

8. Glassman SD, Bridwell K, Dimar JR, Horton W, Berven S, Schwab F: The impact of positive sagittal balance in adult spinal deformity. Spine (Phila Pa 1976) 30:2024-2029, 2005

9. Grubb SA, Lipscomb HJ: Diagnostic findings in painful adult scoliosis. Spine (Phila Pa 1976) 17:518-527, 1992

10. Guler UO, Yuksel S, Yakici S, Domingo-Sabat M, Pellise F, Pérez-Grueso FJS, et al: Analysis of the reliability of surgeons' ability to differentiate between idiopathic and degenerative spinal deformity in adults radiologically. What 
descriptive parameters help them decide? Eur Spine J 25:2401-2407, 2016

11. Ha K, Jang W, Kim Y, Park D: Clinical relevance of the SRS-Schwab classification for degenerative lumbar scoliosis. Spine (Phila Pa 1976):E282-E288, 2016

12. Kleinstueck FS, Fekete TF, Jeszenszky D, Haschtmann D, Mannion AF: Adult degenerative scoliosis: comparison of patient-rated outcome after three different surgical treatments. Eur Spine J 25:2649-2656, 2016

13. Lafage V, Schwab F, Patel A, Hawkinson N, Farcy JP: Pelvic tilt and truncal inclination: two key radiographic parameters in the setting of adults with spinal deformity. Spine (Phila Pa 1976) 34:E599-E606, 2009

14. Liu Y, Liu Z, Zhu F, Qian BP, Zhu Z, Xu L, et al: Validation and reliability analysis of the new SRS-Schwab classification for adult spinal deformity. Spine (Phila Pa 1976) 38:902908, 2013

15. Obeid I, Boissière L, Yilgor C, Larrieu D, Pellisé F, Alanay A, et al: Global tilt: a single parameter incorporating spinal and pelvic sagittal parameters and least affected by patient positioning. Eur Spine J 25:3644-3649, 2016

16. Pellisé F, Vila-Casademunt A, Ferrer M, Domingo-Sàbat M, Bagó J, Pérez-Grueso FJS, et al: Impact on health related quality of life of adult spinal deformity (ASD) compared with other chronic conditions. Eur Spine J 24:3-11, 2015

17. Ploumis A, Transfledt EE, Denis F: Degenerative lumbar scoliosis associated with spinal stenosis. Spine J 7:428-436, 2007

18. Protopsaltis T, Schwab F, Bronsard N, Smith JS, Klineberg $\mathrm{E}$, Mundis G, et al: The T1 pelvic angle, a novel radiographic measure of global sagittal deformity, accounts for both spinal inclination and pelvic tilt and correlates with health-related quality of life. J Bone Joint Surg Am 96:1631-1640, 2014

19. Scheer JK, Hostin R, Robinson C, Schwab F, Lafage V, Burton DC, et al: Operative management of adult spinal deformity results in significant increases in QALYs gained compared to non-operative management: analysis of 479 patients with minimum 2-year follow-up. Spine (Phila Pa 1976) [epub ahead of print], 2017

20. Schwab FJ, Blondel B, Bess S, Hostin R, Shaffrey CI, Smith JS, et al: Radiographical spinopelvic parameters and disability in the setting of adult spinal deformity: a prospective multicenter analysis. Spine (Phila Pa 1976) 38:E803-E812, 2013

21. Schwab F, Ungar B, Blondel B, Buchowski J, Coe J, Deinlein D, et al: Scoliosis Research Society-Schwab adult spinal deformity classification: a validation study. Spine (Phila Pa 1976) 37:1077-1082, 2012

22. Takemoto M, Boissière L, Vital JM, Pellisé F, Perez-Grueso FJS, Kleinstück F, et al: Are sagittal spinopelvic radiographic parameters significantly associated with quality of life of adult spinal deformity patients? Multivariate linear regression analyses for pre-operative and short-term post-operative health-related quality of life. Eur Spine J 26:2176-2186, 2017

23. Terran J, Schwab F, Shaffrey CI, Smith JS, Devos P, Ames $\mathrm{CP}$, et al: The SRS-Schwab adult spinal deformity classifica- tion: assessment and clinical correlations based on a prospective operative and nonoperative cohort. Neurosurgery 73:559-568, 2013

24. Vos T, Flaxman AD, Naghavi M, Lozano R, Michaud C, Ezzati M, et al: Years lived with disability (YLDs) for 1160 sequelae of 289 diseases and injuries 1990-2010: a systematic analysis for the Global Burden of Disease Study 2010. Lancet 380:2163-2196, 2012 (Erratum in Lancet 391:628, 2013)

25. Weinstein SL, Ponseti IV: Curve progression in idiopathic scoliosis. J Bone Joint Surg Am 65:447-455, 1983

26. Youssef JA, Orndorff DO, Patty CA, Scott MA, Price HL, Hamlin LF, et al: Current status of adult spinal deformity. Global Spine J 3:51-62, 2013

\section{Disclosures}

The European Spine Study Group is funded through research grants from DePuy Synthes.

Dr. de Kleuver reports receiving compensation for being on the speakers' bureaus of DePuy and Medtronic, and receiving non-study-related support from AO and the SRS. Dr. Obeid reports being a consultant for DePuy and Medtronic; receiving royalties from Alphatec Spine, Spineart, and Clariance; receiving clinical or research support for this study from DePuy Synthes; and receiving non-study-related clinical research support from Medtronic. Dr. Acaroğlu reports receiving compensation for being on the speakers' bureaus of AOSpine, Medtronic, and Zimmer Biomet; receiving research support from DePuy Synthes and Medtronic; and owning stock in IncredX. Dr. Alanay reports being a consultant for DePuy Synthes and Stryker, and receiving research support from DePuy Synthes. Dr. Kleinstück is a consultant for DePuy and is receiving honoraria for teaching or speaking from DePuy. Dr. Pérez-Grueso reports receiving honoraria for teaching or speaking from K2M and DePuy, and serving as a consultant for these two companies. Dr. Pellisé is a consultant for DePuy Synthes and Zimmer-Biomet and receives non-studyrelated research support from DePuy Synthes, Medtronic, and Zimmer Biomet.

\section{Author Contributions}

Conception and design: Faraj, Holewijn, Pellisé. Acquisition of data: Vila-Casademunt, Obeid, Acaroğlu, Alanay, Kleinstück, Pérez-Grueso, Pellisé. Analysis and interpretation of data: Faraj, De Kleuver, Vila-Casademunt, Holewijn, Obeid, Pellisé. Drafting the article: Faraj, De Kleuver, Pellisé. Critically revising the article: all authors. Reviewed submitted version of manuscript: Faraj, De Kleuver, Holewijn, Obeid, Acaroğlu, Alanay, Kleinstück, Pérez-Grueso, Pellisé. Approved the final version of the manuscript on behalf of all authors: Faraj. Statistical analysis: Faraj. Administrative/technical/material support: Faraj, Vila-Casademunt. Study supervision: De Kleuver, Holewijn, Obeid, Pellisé.

\section{Correspondence}

Sayf S. A. Faraj: Radboud University Medical Center, Nijmegen, The Netherlands.sayf.faraj@radboudumc.nl. 